Proceedings

\title{
Prevalence of Depression and its Associated Risk Factors among University Students in Malaysia: A Pilot Study ${ }^{\dagger}$
}

\author{
Sin Yee Yap ${ }^{1}$, Chai Nien Foo ${ }^{1,2,}$, Yang Mooi Lim ${ }^{1,3}$, Foong Leng Ng, ${ }^{1,4}$, Sherina Mohd-Sidik ${ }^{5}$, Pek Yee Tang, Jagjit \\ Kaur Najar Singh ${ }^{1,7}$ and Pheh Kai Shuen ${ }^{8}$
}

1 Centre for Cancer Research, Faculty of Medicine and Health Sciences, Universiti Tunku Abdul Rahman, PT21144, Jalan Sungai Long, Bandar Sungai Long, 43000 Kajang, Selangor, Malaysia; sinyeeyap24@gmail.com

2 Department of Population Medicine, Faculty of Medicine and Health Sciences, Universiti Tunku Abdul Rahman, PT21144, Jalan Sungai Long, Bandar Sungai Long, 43000 Kajang, Selangor, Malaysia

3 Department of Pre-clinical Science, Faculty of Medicine and Health Sciences, Universiti Tunku Abdul Rahman, Lot PT21144, Jalan Sungai Long, Bandar Sungai Long, 43000 Kajang, Malaysia; ymlim@utar.edu.my

4 Department of Traditional Chinese Medicine, Faculty of Medicine and Health Sciences, Universiti Tunku Abdul Rahman, PT21144, Jalan Sungai Long, Bandar Sungai Long, 43000 Kajang, Selangor, Malaysiai ngfl@utar.edu.my

5 Department of Psychiatry, Faculty of Medicine and Health Sciences, Universiti Putra Malaysia, 43400 UPM Serdang, Selangor, Malaysia; sherina@upm.edu.my

6 Department of Mechatronics and Biomedical Engineering, Lee Kong Chian Faculty of Engineering and Science, Universiti Tunku Abdul Rahman, Lot PT21144, Jalan Sungai Long, Bandar Sungai Long, 43000 Kajang, Malaysia; tangpy@utar.edu.my

7 Department of Nursing, Faculty of Medicine and Health Sciences, Universiti Tunku Abdul Rahman, PT21144, Jalan Sungai Long, Bandar Sungai Long, 43000 Kajang, Selangor, Malaysia; jagjitk@utar.edu.my

8 Department of Psychology and Counselling, Faculty of Arts and Social Science, Universiti Tunku Abdul Rahman, Jalan Universiti, Bandar Barat, 31900 Kampar, Perak, Malaysia; phehks@utar.edu.my

Publisher's Note: MDPI stays neutral with regard to jurisdictional claims in published maps and institutional affiliations.

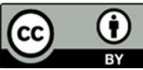

Copyright: (C) 2020 by the authors. Submitted for possible open access publication under the terms and conditions of the Creative Commons Attribution (CC BY) license (http://creativecommons.org/licenses/by/4.0/)

\begin{abstract}
Depression is one of the most common mental health disorders and being an increasing concern in university students who have an increased risk of psychiatric disorders during adulthood. This study aimed to determine the prevalence of depression and its associated risk factors among university students in Malaysia. A cross-sectional pilot study was conducted between $9^{\text {th }}$ and $28^{\text {th }}$ September 2020 among 80 university students in Malaysia. Participants completed online survey questionnaires, including the validated Patient Health Questionnaire (PHQ-9), Constitution in Chinese Medicine Questionnaire (CMCQ), Dysfunctional Attitude Scale (DAS), Depression Anxiety Stress Scale (DASS-21) stress subscale, Perceived Stress Scale (PSS-10) and Rosenberg Self-Esteem Scale (RSES) that assess depression, body constitution, dysfunctional attitude, stress, perceived stress and self-esteem respectively. Socio-demographic data and health status were also recorded. Multiple linear regression analyses were performed to determine the associated risk factors for depression. The overall prevalence of depression among university students was $33.8 \%$, with a greater prevalence among females $(26.3 \%)$ than males $(7.5 \%)$. The multiple regression analysis showed a significant positive relationship between depression and qi-stagnation constitution $(\mathrm{B}=0.089$, $p=0.011$ ). Additionally, significant negative relationships were found between depression with balanced constitution $(B=-0.077, p=0.049)$ and self-esteem $(B=-0.325, p=0.001)$ respectively. Our findings suggest that traditional Chinese medicine body constitution and self-esteem are significant risk factors affecting depression among university students. Identifying risk factors of depression is vital to aid in the early detection of depression among university students.
\end{abstract}

Keywords: depression; traditional Chinese medicine; body constitution; psychological factors

\section{Introduction}

Depression is a common mental health problem and one of the leading causes of disability [1]. Depressive symptoms such as persistent sadness, loss of concentration, and 
lack of energy [2] may interrupt students' daily life and academic performances. They may find it hard to focus in the class or easily fatigue [2] when carrying out daily activities. Depression can also lead to severe and long-term consequences for students, such as health problems [3] and hindering their future success. At its worst, it can lead to suicide [4]. The prevalence of depression among university students in Malaysia is relatively high and alarming, which rates between $27.5 \%$ to $29.3 \%$ in past studies [5-6].

According to traditional Chinese medicine (TCM), each individual has a unique body constitution. Our body constitution can be changed over time and by acquired factors such as diet, lifestyles, and environment [7]. It is what makes us vulnerable to certain diseases [8]. There are nine types of body constitutions, and it can be categorized into balanced and unbalanced constitutions (qi-stagnation, blood-stasis, qi-deficiency, yang-deficiency, yin-deficiency, phlegm-dampness, damp-heat, inherited-special) [7]. Numerous studies have demonstrated the association between body constitutions and depression, especially qi-stagnation and qi-deficiency $[9,10]$. On the other hand, psychological factors associated with depression are dysfunctional attitude, stress, perceived stress, and selfesteem. Previous studies found that depressed group was closely related to selective processing of negative information [11], negative attributional style [12], overgeneralizing, selective abstraction, and negative evaluation of the self, world, and future [13]. Besides, ongoing academic stress [14] and the level of perceived stress [15] can negatively affect students' mental health and severity of depression, respectively. Moreover, many researchers have found that the development of depression was associated with the low level of self-esteem [16,17].

By identifying the risk factors related to depression, it is possible to prevent depression as we can make changes to our diets, learn to cope with stress, and maintain a healthier lifestyle. Therefore, this pilot study aimed to examine the weighted prevalence of depression and to provide some insight into the correlates of depression among university students in Malaysia. It is hypothesized that TCM body constitutions and psychological factors (dysfunctional attitude, stress, perceived stress, and self-esteem) may contribute to the development of depression.

\section{Methods and analysis}

A cross-sectional pilot study online survey was conducted between $9^{\text {th }}$ and $28^{\text {th }}$ September 2020. The participants consisted of Malaysian university students aged between 18 and 30, and data were collected via Google Forms. The sample size for this pilot test was calculated based on the ten observations for each variable with a dropout rate of $25 \%$. Thus, the final estimated sample size for this pilot study was 80 . This study was approved by the Universiti Tunku Abdul Rahman Ethics Committee for research involving human subjects, prior to the commencement of the study.

The survey questionnaires used in this study included the pre-tested and validated Patient Health Questionnaire (PHQ-9) [18], Constitution in Chinese Medicine Questionnaire (CMCQ) [19], Dysfunctional Attitude Scale (DAS) [20], Depression Anxiety Stress Scale (DASS-21) stress subscale [21], Perceived Stress Scale (PSS-10) [22] and Rosenberg Self-Esteem Scale (RSES) [23] to assess depression, body constitution, dysfunctional attitude, stress, perceived stress, and self-esteem respectively. Depression was measured using PHQ-9 because it has equivalent validity to the Diagnostic and Statistical Manual of Mental Disorders, $5^{\text {th }}$ Edition (DSM-V) and showed high sensitivity of $88 \%$ and high specificity of $85 \%$ [24]. Socio-demographic characteristics and health status of the participants were recorded.

Statistical Package for Social Sciences version 25 (SPSS V.25.0) was used to analyze the data. Chi-square was performed to investigate the associations of TCM body constitution, dysfunctional attitude, stress, perceived stress and self-esteem with depression. Relationships between risk factors and depression were then analyzed using multiple linear regressions. All variables with $p$ value less than 0.05 were entered into the multiple linear regression model. The enter method was used. All tests were two-tailed, and the significance level $(\alpha)$ was set at $p$ value of $<0.05$. 


\section{Results}

The overall mean score of PHQ-9 was 7.99 (SD=5.44). According to the PHQ-9 cut off points $\geq 10$, about $33.8 \%(27 / 80)$ participants showed to have depression (Table 1), with a greater prevalence among females (26.3\%) than males $(7.5 \%)$.

Table 1. Prevalence of depression among participants.

\begin{tabular}{cccc}
\hline & Presence of depression (n) & Percentage (\%) \\
\hline Yes & 27 & 33.8 \\
No & 53 & 66.3 \\
Total & 80 & 100.0 \\
\hline
\end{tabular}

A chi-square test of independence showed that there were significant associations between depression with TCM body constitution $(p=0.03)$, dysfunctional attitude $(p<0.001)$, stress $(p<0.001)$, perceived stress $(p=0.01)$, and self-esteem $(p<0.001)$, respectively (Table 2).

Table 2. Associations of traditional Chinese medicine body constitution, dysfunctional attitude, stress, perceived stress, and self-esteem with depression.

\begin{tabular}{|c|c|c|c|c|c|}
\hline \multirow{2}{*}{ Variables } & \multicolumn{2}{|c|}{ Presence of depression } & \multicolumn{2}{|c|}{ Absence of depression } & \multirow{2}{*}{$p$ value } \\
\hline & $\mathbf{n}$ & Percentage (\%) & $\mathbf{n}$ & Percentage (\%) & \\
\hline TCM body constitution $(0-100)$ & & & & & $.027^{*}$ \\
\hline Balanced & 1 & 1.3 & 13 & 16.3 & \\
\hline Unbalanced & 26 & 32.5 & 40 & 50.0 & \\
\hline Dysfunctional attitude (19-133) & & & & & $.000^{*}$ \\
\hline Yes $(>72.54)$ & 11 & 13.8 & 3 & 3.8 & \\
\hline No $(<72.54)$ & 16 & 20.0 & 50 & 62.5 & \\
\hline Stress $(0-42)$ & & & & & $.000^{*}$ \\
\hline High $(\geq 15)$ & 16 & 20.0 & 3 & 3.8 & \\
\hline Low $(0-14)$ & 11 & 13.8 & 50 & 62.5 & \\
\hline Perceived stress $(0-40)$ & & & & & $.014^{*}$ \\
\hline High (14-40) & 27 & 33.8 & 43 & 53.8 & \\
\hline Low $(0-13)$ & 0 & 0 & 10 & 12.5 & \\
\hline Self-esteem (0-40) & & & & & $.000^{*}$ \\
\hline High $(>26.58)$ & 5 & 6.3 & 35 & 43.8 & \\
\hline Low $(<26.58)$ & 22 & 27.5 & 18 & 22.5 & \\
\hline
\end{tabular}

* significant at $p<0.05$. Derived score $\geq 60$ in balanced constitution section and $<30$ in other constitution sections was considered as balanced constitution, otherwise were unbalanced constitution.

Multiple linear regression analysis was performed to examine the relationships between depression and various potential predictors. The multiple regression model with all six predictors produced $\mathrm{R}^{2}=0.740, \mathrm{~F}(6,73)=34.71, p<0.001$. Details of the analysis results are shown in Table 3. Qi-stagnation constitution $(B=0.089, p=0.011)$ was positively and significantly associated with depression, indicating that the participants with a qi-stagnation constitution tend to have a higher risk of depression. Whereas, balanced constitution $(\mathrm{B}=-$ $0.077, p=0.049)$ and self-esteem $(B=-0.325, p=0.001)$ were negatively associated with depression, indicating that participants with a balanced constitution or high self-esteem have a lower risk of depression.

Table 3. Summary statistics and results from the regression analysis.

\begin{tabular}{|c|c|c|c|c|c|c|c|c|}
\hline \multirow{2}{*}{$\begin{array}{c}\text { Variables } \\
\text { TCM body constitution } \\
\text { (CMCQ) }\end{array}$} & \multirow{2}{*}{$\begin{array}{c}\text { Mea } \\
\mathbf{n}\end{array}$} & \multirow{2}{*}{$\begin{array}{l}\text { Standard de- } \\
\text { viation }\end{array}$} & \multicolumn{3}{|c|}{$\begin{array}{l}\text { Simple linear regres- } \\
\text { sion }\end{array}$} & \multicolumn{3}{|c|}{$\begin{array}{l}\text { Multiple linear regres- } \\
\text { sion }\end{array}$} \\
\hline & & & B & $\beta$ & $p$ & B & $\beta$ & $p$ \\
\hline Qi-stagnation (0-100) & $\begin{array}{c}37.36 \\
6\end{array}$ & 13.314 & .177 & .427 & $.000^{*}$ & .089 & .214 & $.011^{*}$ \\
\hline Blood-stasis (0-100) & $\begin{array}{c}38.98 \\
9\end{array}$ & 16.258 & -.035 & -.102 & .343 & & & \\
\hline
\end{tabular}




\begin{tabular}{|c|c|c|c|c|c|c|c|c|}
\hline Qi-deficiency (0-100) & $\begin{array}{c}40.85 \\
9\end{array}$ & 13.633 & .011 & .027 & .845 & & & \\
\hline Yang-deficiency (0-100) & $\begin{array}{c}30.13 \\
4\end{array}$ & 15.950 & -.051 & -.148 & .140 & & & \\
\hline Yin-deficiency (0-100) & $\begin{array}{c}36.83 \\
6\end{array}$ & 14.210 & -.027 & -.070 & .524 & & & \\
\hline Phlegm-dampness (0-100) & $\begin{array}{c}28.67 \\
2\end{array}$ & 15.324 & .023 & .064 & .562 & & & \\
\hline Damp-heat (0-100) & $\begin{array}{c}26.42 \\
9\end{array}$ & 13.562 & .003 & .007 & .943 & & & \\
\hline Inherited special $(0-100)$ & $\begin{array}{c}31.42 \\
9\end{array}$ & 16.784 & .018 & .056 & .545 & & & \\
\hline Balanced (0-100) & $\begin{array}{c}56.44 \\
5\end{array}$ & 13.168 & -.230 & -.548 & $.000^{*}$ & -.077 & -.185 & $.049^{*}$ \\
\hline $\begin{array}{l}\text { Dysfunctional attitude } \\
\text { (DAS) (19-133) }\end{array}$ & $\begin{array}{c}55.32 \\
5\end{array}$ & 17.211 & .188 & .587 & $.000^{*}$ & .036 & .111 & .174 \\
\hline Stress (DASS-21) (0-42) & $\begin{array}{c}10.62 \\
5\end{array}$ & 8.381 & .459 & .697 & $.000^{*}$ & .117 & .178 & .053 \\
\hline $\begin{array}{c}\text { Perceived stress (PSS-10) (0 } \\
40)\end{array}$ & $\begin{array}{c}19.62 \\
5\end{array}$ & 5.862 & .656 & .696 & $.000^{*}$ & .091 & .097 & .334 \\
\hline Self-esteem (RSES) (0-40) & $\begin{array}{c}26.57 \\
5\end{array}$ & 5.081 & -.776 & -.714 & $.000^{*}$ & -.325 & -.299 & $.001^{*}$ \\
\hline
\end{tabular}

* significant at $p<0.05$; higher score indicates higher level of TCM body constitution (qi-stagnation, blood-stasis, qi-deficiency, yang-deficiency, yin-deficiency, phlegm-dampness, damp-heat, inherited special, and balanced), dysfunctional attitude, stress, perceived stress, and self-esteem, respectively.

\section{Discussion}

The results of the present study found that the prevalence rate of depression among university students was $33.8 \%$, which is higher than previous similar research conducted among university students in public and private universities in the Klang valley [5,6]. In view of the current pandemic outbreak in Malaysia, the increase in depression might due to changes in the daily lifestyles [25].

The present study found that qi-stagnation was positively and significantly associated with depression among university students, which in accordance with similar studies focused on university students [9,10]. Qi-stagnation symptoms included emotionally unstable, easily worried, frequently sighing, low spirit, and low mood [26]. Qi can become stagnate as a result of excessive thought, anxiety, and stress [26]. In TCM, the liver is in charge of dispersion and dredging to regulate qi's movement throughout the body and emotions [26]. During university, the students may experience excessive stress and anxiety as they struggle with their studies, experience financial pressure, and be concerned for their future. These factors could affect the function of the liver, resulting in the interruptions of qi and blood which can lead to a variety of problems, including mood swings and depression [26]. Additionally, poor sleep quality and insomnia in university students [27] could have influenced the liver's blood storing ability, thus affecting its dispersion and dredging function, which will then cause qi stagnation [26].

Balanced constitution was negatively associated with depression, which means university students with a balanced constitution are less likely to develop depression. Students with a balanced constitution have a balanced yin-yang, qi, and blood in their bodies [26]. They usually have stable emotional or mental states and are adaptable to environmental changes [264]. Often, these students have relatively healthier lifestyles compared to others with unbalanced constitutions [26]. They may be involved in more physical activities and have a balanced diet. This makes them less susceptible to depression as previous research has demonstrated that lifestyle changes can enhance mood and mental health [25]. Therefore, understanding the concept of body constitution can help prevent and treat depression by changing the factors mentioned above. 
Self-esteem is a person's overall sense of his or her value or worth [28]. The causes of low self-esteem included unhappy childhood, poor academic performance, and ongoing stressful life events such as relationship breakdown and financial trouble [29]. People with low self-esteem are more likely to feel sad and lonely. Besides, they are more sensitive to rejection. In a study by Mann et al [30], the researchers found that low self-esteem may lead to high-risk behavior or inappropriate coping behaviors that can increase the risk of depression. Generally, self-esteem is malleable during adolescence and becomes relatively stable across one's life [31], indicating that self-esteem in youth may have a critical role in determining the risk of depression during one's later life stages. Students with low selfesteem tend to develop high-risk behaviors such as alcohol consumption and marijuana use due to peer pressure [32]. Engaging in these health promising behaviors could contribute to the development of mental illnesses, including depression.

The limitation of the representativeness of the study sample is due to the sampling method used. A more detailed study will be conducted using larger sample size and probability sampling method to confirm the current findings.

\section{Conclusions}

The prevalence rate of depression found in the present study is relatively high. As for predictors of depression, qi-stagnation constitution is a motivator for the occurrence of depression. While balanced constitution and high self-esteem are the inhibitors of the development of depression. Addressing mental health during and after this global health crisis should be an increasing public health concern in university students.

Author Contributions: Conceptualization, C.N.F., Y.M.L., F.L.N. and P.Y.T.; methodology, C.N.F., Y.M.L., F.L.N. and S.Y.Y.; validation, C.N.F., Y.M.L., F.L.N., S.Y.Y., K.S.P. and S.M.-S.; formal analysis, C.N.F. and S.Y.Y.; investigation, C.N.F., Y.M.L., F.L.N. and S.Y.Y.; data curation, S.Y.Y.; writing-original draft preparation, S.Y.Y.; writing - review and editing, C.N.F., Y.M.L., F.L.N., S.Y.Y., K.S.P., S.M.-S., P.Y.T. and J.K.N.S.; supervision, C.N.F., Y.M.L. and F.L.N.; project administration, C.N.F., Y.M.L., F.L.N. and S.Y.Y.; funding acquisition, C.N.F., Y.M.L., F.L.N., P.Y.T., S.M.-S. and J.K.N.S. All authors have read and agreed to the published version of the manuscript.

Funding: This research was funded by Universiti Tunku Abdul Rahman Research Fund (UTARRF), project number IPSR/RMC/UTARRF/2019-C2/F01.

Acknowledgments: The authors thank the students, without whom the research would not be possible.

Conflicts of Interest: The authors declare no conflict of interest.

\section{References}

1. Who Health Organization: depression fact sheet number 369. Available online: https://www.who.int/news-room/factsheets/detail/depression (accessed on 7/11/2020).

2. Diagnostic and Statistical Manual of Mental Disorders, 5th ed.; American Psychiatric Publishing: Washington, DC, USA, 2013.

3. Adams, T. B.; Wharton, C.; Quilter, L.; Hirsch, T. The Association between Mental Health and Acute Infectious Illness among a National Sample of 18- to 24-Year-Old College Students. Journal of American college health: J of ACH 2008, 56(6), 657-664. https://doi.org/10.3200/JACH.56.6.657-664

4. Wang, Y. H.; Shi, Z. T.; Luo, Q. Y. Association of Depressive Symptoms and Suicidal Ideation among University Students in China: A Systematic Review and Meta-Analysis. Medicine (Baltimore) 2017, 96(13), e6476. https://doi.org/10.1097/MD.0000000000006476

5. Shamsuddin, K.; Fadzil, F.; Ismail, W. S. W.; Shah, S. A.; Omar, K.; Muhammad, N. A.; Jaffar, A.; Ismail, A.; Mahadevan, R. Correlates of Depression, Anxiety and Stress among Malaysian University Students. Asian Journal of Psychiatry 2013, 6(4), 318323. https://doi.org/10.1016/j.ajp.2013.01.014

6. Gan, W. Y.; Nasir, M. T. M.; Zalilah, M. S.; Hazizi, A. S. Disordered eating behaviors, depression, anxiety and stress among Malaysian university students. College Student Journal 2011, 45(2), 296.

7. Wang, Q. Constitution Science of Traditional Chinese Medicine. People's Medical Publishing House 2005.

8. Sun, L. J. Study and Interpret of Body Constitution in Chinese Medicine. Zhongguo Zhongyiyao Chubanshe 2008, 3-5.

9. Qiu, N; Xu, Y. The relationship between body constitutions and depression among Chinese medicine students. China Journal of Health Psychology 2016, 4.

10. Zhang, X. C.; Zhang, X. Q.; Yang, T.; Zhang, H. Relationship Between Chinese Medicine Constitution and Depression of 671 College Students in Nanjing. Journal of Nanjing University of Traditional Chinese Medicine (Social Science Ed) 2019, 20(4), $245-249$. 
11. Beck, A. T.; Clark, D. A. Anxiety and depression: An information processing perspective. Anxiety Research 1988, 1(1), 23-26.

12. Kaslow, N. J.; Rehm, L. P.; Pollack, S. L.; Siegel, A. W. Attributional style and self-control behavior in depressed and nondepressed children and their parents. Journal of Abnormal Child Psychology 1988, 16(2), 163- 175.

13. Orchard, F.; Reynolds, S. The combined influence of cognitions in adolescent depression: Biases of interpretation, selfevaluation, and memory. British Journal of Clinical Psychology 2018, 57(4), 420-435.

14. Pascoe, M. C.; Hetrick, S. E.; Parker, A. G. The impact of stress on students in secondary school and higher education. International Journal of Adolescence and Youth 2019, 25(1), 104-112.

15. Pozzebon, D.; Piccin, C. F.; Silva, A. M. T. D.; Correa, E. E. R. Relationship among perceived stress, anxiety, depression and craniocervical pain in nursing professionals under stress at work. Fisioterapia Em Movimento 2016, $29(2), 377-385$. https://doi.org/10.1590/0103-5150.029.002.ao17

16. Beck, A. T. Depression: Clinical, experimental, and theoretical aspects; New York, Hoeber Medical Division, Harper \& Row: New York, 1967.

17. Sowislo, J. F.; Orthe, U. Does low self-esteem predict depression and anxiety? A meta-analysis of longitudinal studies. Psychological Bulletin 2013, 139(1), 213-240. doi:10.1037/a0028931

18. Kroenke, K.; Spitzer, R. L.; Williams, J. B. The PHQ-9: Validity of a Brief Depression Severity Measure. J Gen Intern Med 2001, 16(9), 606-613. https://doi.org/10.1046/j.1525-1497.2001.016009606.x

19. Wang, Q.; Zhu, Y. B.; Xue, H. S.; Li, S. Primary Compiling of Constitution in Chinese Medicine Questionnaire. Chinese Journal of Clinical Rehabilitation 2006, 10, 12-14.

20. Weissman, A. N. The Dysfunctional Attitude Scale: A Validation Study. Dissertation Abstracts International 1979, 40(3-B), 13891390.

21. Lovibond, S. H.; Lovibond, P. F. Manual for the Depression Anxiety Stress Scales, 2nd Edition; Psychology Foundation: Sydney, 1995.

22. Cohen, S.; Kamarck, T.; Mermelstein, R. A Global Measure of Perceived Stress. Journal of Health and Social Behavior 1983, 24(4), 385-396. https://doi.org/10.2307/2136404

23. Rosenberg, M. Society and the Adolescent Self-Image; Princeton University Press: Princeton, 1965.

24. Levis, B.; Benedetti, A.; Thombs, B. D. Accuracy of Patient Health Questionnaire-9 (PHQ-9) for screening to detect major depression: individual participant data meta-analysis. Bmj 2019, l1476. https://doi.org/10.1136/bmj.11476.

25. Dale, H.; Brassington, L.; King, K. The Impact of Healthy Lifestyle Interventions on Mental Health and Wellbeing: A Systematic Review. Mental Health Review Journal 2014, 19(1), 1-26. https://doi.org/10.1108/MHRJ-05-2013-0016

26. Xing, Y. R.; Zhang, X. D.; Huang, G, P.; Sun, L. J.; Qiao, W. B. Basic Theory of Chinese Medicine; Shaanxi Science and Technology Press: China, 2016

27. Abdalqader, A. M.; Ariati, A. I.; Faisal, G. H.; Faez, A. M.; Ariff, F. M. Prevalence of Insomnia and Its Association with Social Media Usage Among University Students in Selangor, Malaysia, 2018. Folia Medica Indonesiana 2018, 54(4), $289-293$. https://doi.org/10.20473/FMI.V54I4.10715

28. Orth, U.; Robins, W. Understanding the link between low self-esteem and depression. Current Directions in Psychological Science 2013, 22(6), 455-460. doi:10.1177/0963721 413492763

29. Better Health Channel Self-esteem. Available online: https://www.betterhealth.vic.gov.au/health/healthyliving/self-esteem (accessed on 1/1/2021).

30. Mann, M. Self-esteem in a broad-spectrum approach for mental health promotion. Health Education Research 2004, 19(4), 357372.

31. Trzesniewski, K. H.; Donnellan, M. B.; Robins, R. W. Stability of self-esteem across the life span. Journal of Personality and Social Psychology 2003, 84(1), 205-220. https://doi.org/10.1037/0022-3514.84.1.205

32. Park, K. W.; Yang, T. C. The Long-term Effects of Self-Esteem on Depression: The Roles of Alcohol and Substance Use During Young Adulthood. The Sociological Quarterly 2017, 3, 429-446. https://doi.org/10.1080/00380253.2017.1331718 